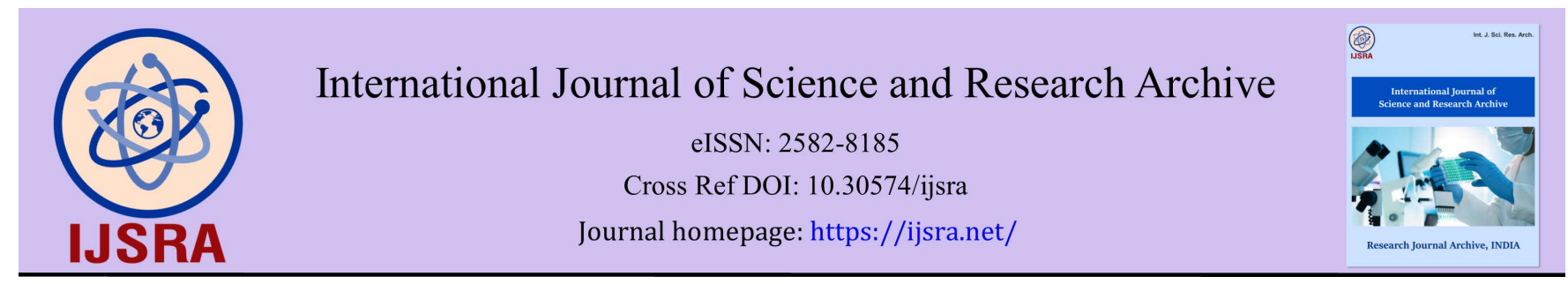

(REVIEW ARTICLE)

\title{
Present scenario of policies \& hazards related to alcohol in India
}

\author{
Tapan Kumar Mahato ${ }^{1, *}$ and Vishwakarma Singh ${ }^{2}$ \\ 1 Department of Pharmaceutical Analysis, B. Pharmacy College Rampura, PO Kakanpur, Taluka Godhra, District \\ Panchmahal, Gujarat, India-388713. \\ 2 Department of Pharmacology, B. Pharmacy College Rampura, PO Kakanpur, Taluka Godhra, District Panchmahal, \\ Gujarat, India-399713.
}

International Journal of Science and Research Archive, 2021, 03(02), 097-106

Publication history: Received on 21 August; revised on 23 September 2021; accepted on 25 September 2021

Article DOI: https://doi.org/10.30574/ijsra.2021.3.2.0141

\begin{abstract}
Although the use of various psychoactive substances such as alcohol, cannabis and opioids has been observed in India for centuries. Use of psychoactive substances impacts on academic, social, psychological, economical and physiological development of people with their families negatively. Alcoholic beverages are the most important product of global addiction demand, which is a reason of many deaths and diseases worldwide. Alcohol consumption is a major problem in India because of the various reasons like socio-cultural, difference in alcohol policies and practices state wise, lack of awareness of alcohol related problems, false mass media propaganda, various patterns of alcohol consumption and as a symbol of status both in urban and rural areas across the country. As per people's opinion, they consumes it because it induces feeling of relaxation and tranquility, suppress anxiety and increases confidence. However with increasing dose, pleasant euphoric starts which means they feels that they are in heaven and that gives way to feelings of depression. That's why this is called as substance of abuse. This review article focuses on ethyl alcohol (alcohol),its pharmacology,policies in India, different patterns of drinking, prevalence of alcohol consumption globally and nationally, medical and other consequences like suicide and road accidents, harmful effects on the mental, physical and social health with treatment options for alcoholism.
\end{abstract}

Keywords: Alcoholic beverages; Intoxication of alcohol abuse; Patterns of alcohol consumption; Legal drinking age; Treatment option of alcoholism; Alcohol policy in India

\section{Introduction}

\subsection{Alcohol}

Alcohol can be categorized into four types i.e. methyl alcohol, ethyl alcohol, propyl alcohol and butyl alcohol. Ethyl Alcohol or ethanol is the type used in the production of alcoholic beverages [1]. It is consumed as an alcoholic beverage in diluted concentrations of absolute (i.e., 100\%) ethyl alcohol [2]. Except ethyl alcohol, methyl, propyl and butyl alcohol are not used in alcoholic beverages and if these are consumed even in relatively small doses, it can lead to blindness or even death. Alcohol is produced by the process of fermentation of yeast, sugars and starches [1]. For production of wine, beer and liquors, fruits (grapes) and grains (barley and wheat) are most commonly used. Other plants like cactus or sugar cane may also be used in liquor production [3].

\footnotetext{
${ }^{*}$ Corresponding author: Tapan Kumar Mahato

Department of Pharmaceutical Analysis, B. Pharmacy College Rampura, PO Kakanpur, Taluka Godhra, District Panchmahal, Gujarat, India-388713.
}

Copyright (c) 2021 Author(s) retain the copyright of this article. This article is published under the terms of the Creative Commons Attribution Liscense 4.0. 


\subsection{Chemistry of Ethyl Alcohol or Ethanol [4]}

Ethyl alcohol is a colorless, volatile liquid with a characteristic odor and a pungent taste. It is a compound of carbon, hydrogen and oxygen. The chemical formula for ethyl alcohol is $\mathrm{C}_{2} \mathrm{H}_{5} \mathrm{OH}$ or $\mathrm{CH}_{3} \mathrm{CH}_{2} \mathrm{OH}$. Ethyl alcohol consists of two carbon atoms, five hydrogen atoms and an $\mathrm{OH}$ group. In simple words we can say hydroxyl group (-OH) is attached to ethane. Structural Formula of ethyl alcohol consists of carbon atoms which are sp3 hybridized i.e. they have a free rotation and it is represented as -<smiles>CCO</smiles>

Figure 1 Structural formula of ethyl alcohol

There are various types of alcoholic beverages which are consumed across the world. Alcoholic beverages differs by their content of alcohol and production method. The most common alcoholic beverages are beer, wine, whisky, rum, vodka, gin and brandy [1].

\section{Alcohol content in different alcoholic beverages}

Different alcoholic beverages available in market gave different concentration or content of alcohol. Table 1 below provides us information about alcohol content in different alcoholic beverages.

Table 1 Alcohol Content in Alcoholic Beverages [5]

\begin{tabular}{|l|l|c|}
\hline S.NO. & Alcoholic beverages & $\begin{array}{c}\text { Ethyl alcohol content } \mathbf{a t}_{\mathbf{2}} \mathbf{C}^{\mathbf{C}} \\
\text { (\% bolume), max }\end{array}$ \\
\hline 1 & Brandy or grape brandy & $36-50$ \\
\hline 2 & Blended brandy & $36-50$ \\
\hline 3 & Country liquor or plain country liquor & $19-43$ \\
\hline 4 & Blended country liquor & $19-43$ \\
\hline 5 & Fenny (Cashew) & $19-43$ \\
\hline & Fenny (Coconut) & $19-43$ \\
\hline 6 & Gin & $36-50$ \\
\hline 7 & Liqueur or Cordial Aperitif & $15-50$ \\
\hline 8 & Rum & $36-50$ \\
\hline 9 & White rum & $36-50$ \\
\hline 10 & Vodka & $36-50$ \\
\hline 11 & Whisky & $36-50$ \\
\hline 12 & Malt or grain whisky or single malt & $36-50$ \\
\hline 13 & Blended whisky & $36-50$ \\
\hline 14 & Pot distilled spirits & $36-50$ \\
\hline 15 & Table or grape wine (White) & $7-15.5$ \\
\hline & Table or grape wine (Red) & $7-15.5$ \\
\hline 16 & Wine with carbon dioxide & $7-15.5$ \\
\hline 17 & Fortified wine & $15-24$ \\
\hline & & \\
\hline & & \\
\hline
\end{tabular}




\begin{tabular}{|l|l|c|}
\hline 18 & Fruit wine (other than grape wine) & $7-15.5$ \\
\hline 19 & Cider & $0.5-9$ \\
\hline 20 & Perry & $0.5-9$ \\
\hline 21 & Wine from other agricultural and plant sources & $1.5-8$ \\
\hline 22 & Beer (Regular) & $0.5-5$ \\
\hline 23 & Beer (Strong) & $5-8$ \\
\hline & i. Draught beer (Regular) & $0.5-5$ \\
\hline & ii. Draught beer (Strong) & $5-8$ \\
\hline
\end{tabular}

\section{Pharmacology of Ethyl Alcohol (Alcohol)}

Alcohol is highly soluble in water and its absorption decreased by fatty food. Alcohol when consumed, gets distributes into body water. Blood-alcohol concentration (BAC) is concentration of alcohol in blood. The concentration of alcohol in blood depends on many factors like weight, body fat, amount of alcohol consumed, time frame of alcohol consumption and effect of food. BAC becomes higher in cases like drinking over shorter time periods, larger quantities and on an empty stomach. BAC is expressed in $\mathrm{g} / \mathrm{dL}$ (grams per deciliter).

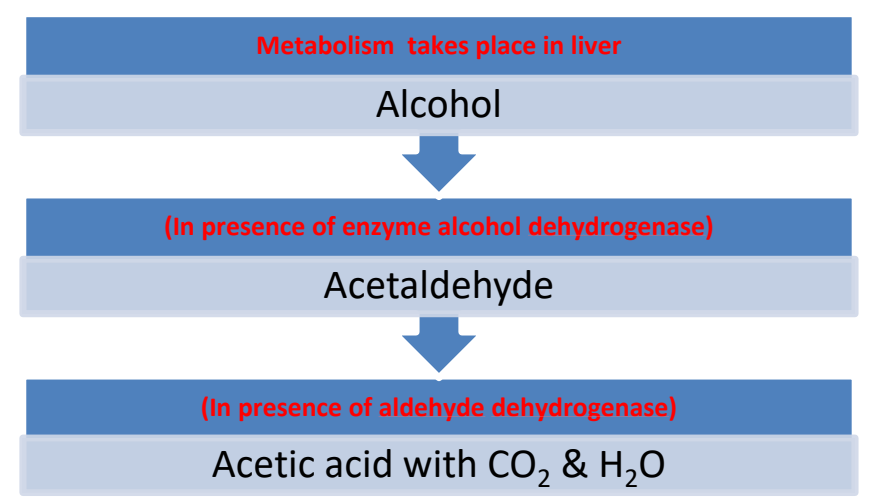

Figure 2 Flow chart showing the Pharmacology of alcohol

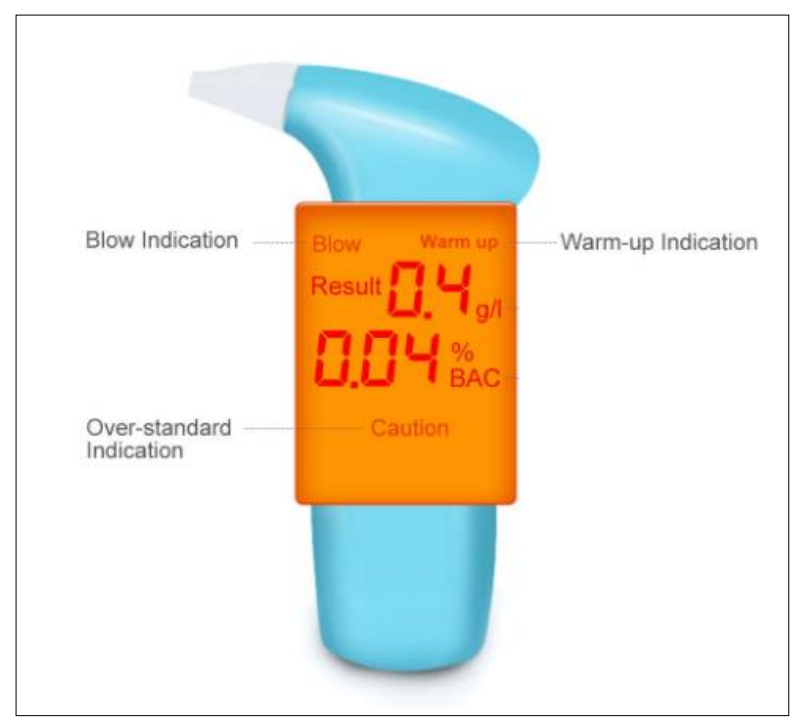

Figure 3 Portable Breathalyzer Alcohol Tester (Courtesy: www.smartnetk.com) 
Alcohol is metabolized mostly in the liver. The enzyme alcohol dehydrogenase converts alcohol to acetaldehyde (a sympathomimetic toxin responsible for the 'hangover' effect). Then the aldehyde dehydrogenase metabolize acetaldehyde to acetic acid with carbon dioxide and water. Figure 2 shows this process in flowchart.

Small amounts of alcohol is excreted through the urine, lungs i.e. breath and sweat. Ethyl alcohol excretion by the lungs constitutes the basis for the to check the suspects of drinking and driving Breathalyzer test is used which works on the principle of measurement of ethyl alcohol excreted by the lungs. Figure 3 shows a breathalyzer. Alcohol increases the inhibitory neurotransmitter GABA (gamma amino butyric acid) and decreases the nerves signals along that neuronal pathway. Due to this action, alcohol is known as a central nervous system (CNS) depressant which results in decreased both cognitive and physical capacities. Alcohol in combination with other CNS depressants like opiates, barbiturates or benzodiazepines can lead to synergistic and dangerous effects [6].

\section{Intoxication of Alcohol abuse}

Health problems like liver and cardiovascular disease, cancer and nervous system damage may arise due to long term consumption of alcohol. Apart from these psychiatric problems such as depression, anxiety and antisocial personality disorder may also arise [7]. Lot of behavior changes are marked due to alcohol consumption. Even low doses can cause impaired judgment and coordination, induces feelings of relaxation and tranquility, suppress anxiety and in some cases, people observe the feeling of confidence. However with increase in dose, euphoria begins which gives way to feelings of depression. Intoxication occurs because the liver is unable to metabolize more than 29.6 ml of alcohol every hour. Therefore, when a person consumes more alcohol than the body cannot metabolize, intoxication occurs. Intoxication can generally last anywhere from one to 12 hours, and the after-effects ("hang-over") of intoxication can last 24 hours or more. Repeated use of alcohol increases the tolerance which leads to greater amounts to achieve the desired effects. Once the body develops dependence to alcohol, a sudden cessation of its intake is likely to produce withdrawal symptoms. Withdrawal symptoms can be life-threatening and include severe anxiety, tremors, hallucinations, and convulsions.

Alcohol can be life threatening if the amount of alcohol reaches a concentration above 460 milligrams of alcohol per 100 milliliters of blood $(0.46 \mathrm{~g} / \mathrm{dL})$. Severe alcohol intoxication can lead to death from respiratory depression and this can be more dangerous if alcohol gets combined with CNS depressant medications [8]. Alcohol intoxication give rise to crimeswhich include sexual/physical assault, rape, exploitation of women in commercial sex work and homicide [9].

Table 2 Use of Alcohol as Psychoactive substance in India [10]

\begin{tabular}{|l|c|}
\hline Population (10 to 75years) uses alcohol nationally & $\mathbf{1 4 . 6 \%}$ (about 16 Crore) \\
\hline Men's percentage & $27.3 \%$ \\
\hline Women's percentage & $1.6 \%$ \\
\hline Country liquor/Desi sharab & $30 \%$ \\
\hline Spirits/Indian made foreign Liquor & $30 \%$ \\
\hline
\end{tabular}

\section{Various patterns of alcohol consumption}

Table 3 Various patterns of alcohol consumption

\begin{tabular}{|l|l|}
\hline Social Drinking & $\begin{array}{l}\text { Men not more than two drinks per day. Women not more than one drink per day } \\
{[3] .}\end{array}$ \\
\hline Binge drinking & Men five or more drinks on a single occasion. Women four or more drinks [11]. \\
\hline Harmful drinking pattern & $\begin{array}{l}\text { According to WHO, The consumption pattern which results in physical or } \\
\text { psychological harm to the individual or society [12]. }\end{array}$ \\
\hline Hazardous drinking pattern & The quantity or pattern which results risk for adverse health events [11]. \\
\hline Alcohol dependence & $\begin{array}{l}\text { Conditions of alcoholics like a strong desire to consume alcohol, difficulties in } \\
\text { controlling, persisting in its use despite harmful consequences, giving priority to } \\
\text { alcohol use than to other activities and obligations, increased tolerance and } \\
\text { sometimes a physiological withdrawal state [13]. }\end{array}$ \\
\hline
\end{tabular}




\section{Disease burden because of Alcohol consumption}

According to recent data published by the World Health Organization (WHO), the total per capita consumption of alcohol by individuals above 15 years of age is $6.2 \mathrm{~L}$ of pure alcohol per year, which equals $13.5 \mathrm{~g}$ of pure alcohol per day. However, there is a wide variation between the WHO regions and member states. Nearly $5.1 \%$ of the global burden of disease is attributable to alcohol consumption, and it causes nearly 3.3 million deaths every year [1].

According to the reports of Global information system on alcohol and health (GISAH) globally, approximately 3.3 million deaths (5.9\% of all deaths) per annum attributable to the harmful use of alcohol and liquor consumption is strongly related to $5.1 \%$ of the global burden of disease [15].

WHO's Global status report on alcohol and health 2014, distributed the deaths due to alcohol consumption which is mentioned in Table 4.

Table 4 Global deaths distributed to alcohol consumption [1]

\begin{tabular}{|l|c|}
\hline Highest prevalence of Alcohol use disorder (AUD) & Europe (7.5\%) \\
\hline Lowest prevalence of Alcohol use disorder (AUD) & $\begin{array}{c}\text { Eastern Mediterranean regions } \\
\text { (Afghanistan, Bahrain and Egypt) }\end{array}$ \\
\hline Deaths caused by & $50 \%$ \\
\hline Liver cirrhosis & $30 \%$ \\
\hline Oral and pharyngeal cancers & $22 \%$ \\
\hline Interpersonal violence & $22 \%$ \\
\hline Self-harm & $15 \%$ \\
\hline Traffic injuries & $12 \%$ \\
\hline Tuberculosis & $12 \%$ \\
\hline Liver cancer & \\
\hline
\end{tabular}

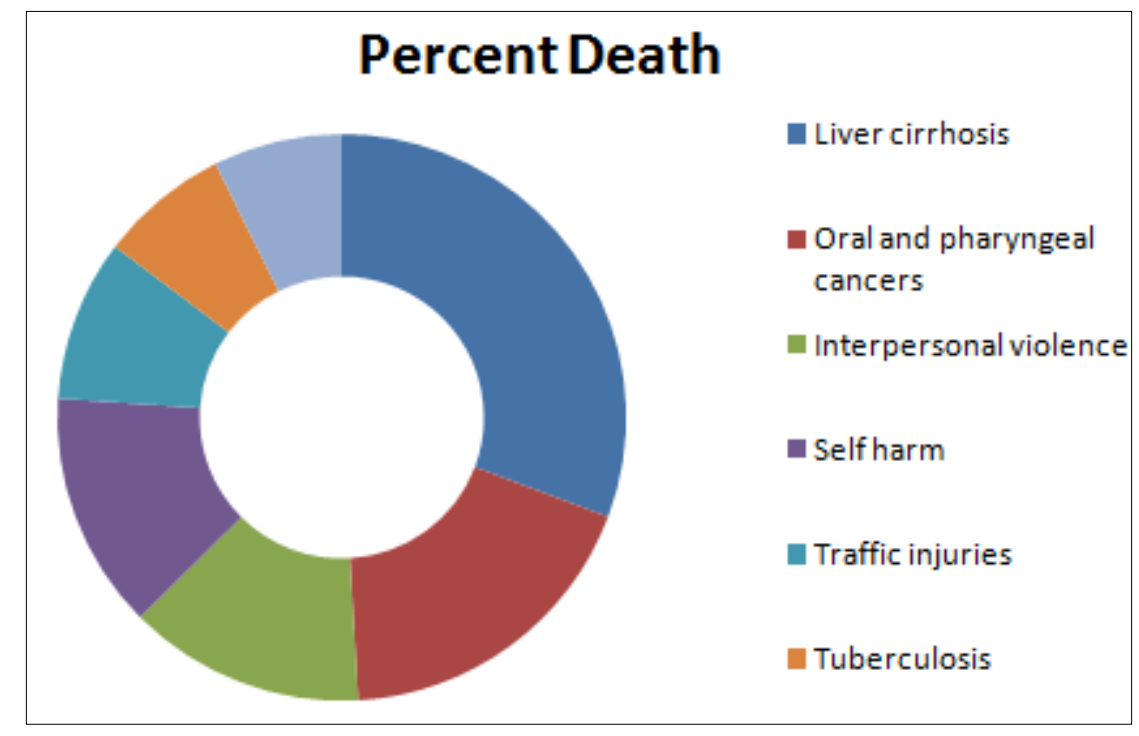

Figure 4 Causes and their percent deaths due to alcohol consumption

At the national level, 33.1\% of all the road traffic accident deaths were attributable to drunk and driving in 2012. As per the National Mental Health Survey of India 2015-16, the prevalence of alcohol use disorder is 9\% in adult men. In India, 
$5.4 \%$ deaths were found due to alcohol. On comparing all deaths due to liver cirrhosis, around $62.9 \%$ was found due to alcohol use [14].

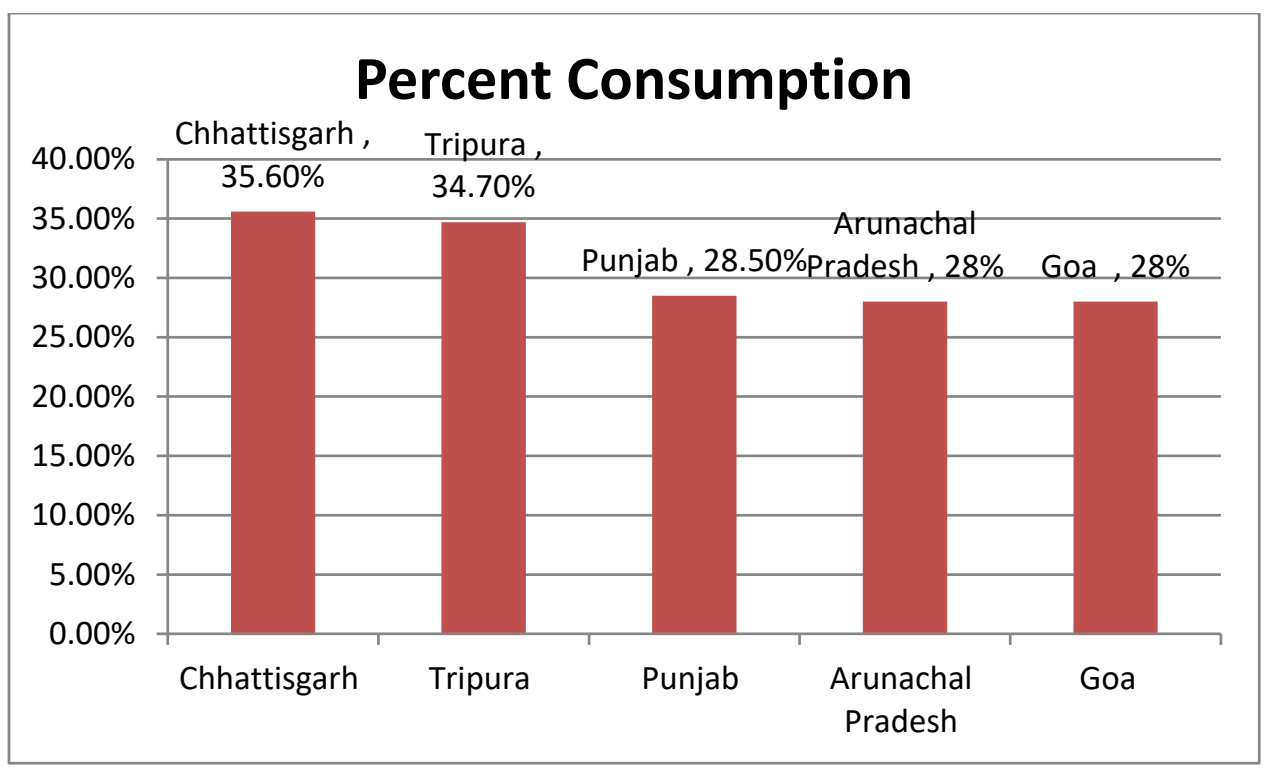

Figure 5 States with highest prevalence of alcohol

\section{Medical consequences of Alcohol use}

Gastrointestinal (GI) complications: vomiting, hyperacidity, peptic ulcer disease [13]. In 2012, WHO proclaimed that age standardized death rates (ASDR) of 39.5 per 1 lakh population and 19.6 per one lakh population globally were owing to alcohol related liver diseases (Cirrhosis of liver) [15].

Cancer: Breast cancer, oral and esophageal cancers, rectal cancers, cancers of the pharynx, oral cavity, esophagus and larynx [16].

Changes in the genitourinary system: decrease in the erectile capacity in men, decrease in ejaculate volume and a low sperm count [17] high-risk of HIV infection [18].

Muscular changes: skeletal muscle weakness, lower bone density [17], avascular necrosis of the femoral head [19].

Neurological complications: blackouts, blurred vision, impaired memoryand slowerreactiontimes [20] alcoholic tremors, myopathy, Wernicke's encephalopathy and cerebellar degeneration [21].

Psychiatric complications: increased risk for suicide, personality disorders and risk-taking behaviors [21].

\subsection{Other consequences}

\subsubsection{Suicides due to alcohol consumption}

As per a comparative study carried out by Gururaj in Bangalore, cases of suicide are nearly 25 times more among the alcohol users compared to non-alcoholics [22]. Another study done by Vijayakumar et al., in Chennai found that suicide rates were higher among alcohol users as compared with non-alcoholic [23].

\subsubsection{Road traffic accidents due to alcohol consumption}

Drunken driving (Motor vehicle Act): Several laws are there governing drunken driving in India. The BAC limits are fixed at $\mathbf{0 . 0 3 \%}$. As per the Motor Vehicle Act, any person whose BAC values are found to be more than this limit are booked under the first offence and may be fined about INR2,000 to 10,000 and/orhe or she may face a maximum of 6 months to 4 years imprisonment [32]. 
In a study conducted by the National Institute of Mental Health and Neurosciences (NIMHANS) in 12 major hospitals of Bangalore city, it was foundthat nearly $28 \%$ of injuries because of road traffic accidents were directly attributable to alcohol. The roadside survey revealed that nearly up to $40 \%$ of the drivers were under the influence of alcohol [24, 25]. In a study done by Aditya et al., it was found that $20 \%$ of the fatal road traffic accidents were because of alcohol use. The blood alcohol concentration (BAC) of 38\% of those alcohol users were above the permissible limits [26]. According to the latest data released by the National Crime Records Bureau (2015), Tamil Nadu recorded the highest number of drunk and driving accidents in the country [27].

\section{Beneficial effects of Alcohol}

It is reported that consumption of small amounts of alcohol is beneficial for cardiovascular health, particularly red wine because it contains Resveratrol and Flavonoids which acts as antioxidant and provides cardioprotective effects to the heart. The role of antioxidants is to prevent heart disease by increasing levels of high-density lipoprotein which is called as good cholesterol and protects artery damage. Moderate drinking means neither less nor more which means two drinks per day for men and one drink per day for women. A drink means $355 \mathrm{ml}$ of beer, $148 \mathrm{ml}$ of wine etc. Moderate consumption of alcohol raises high density lipoproteins, prevents formation of blood clots and also prevents artery damage due to low density lipoprotein which is called as bad cholesterol. It does not mean that everybody starts drinking for prevention of heart disease because it leads to other health problems and a man become addictive [28].

\section{Alcohol policy in India}

According to the National Crime Records Bureau of India, the different crimes that are related to alcohol consumption fall under four major acts namely, the Prohibition Act, Gambling Act, Psychotropic Substance Act and Excise Act [9]. In India, State Governments have the power to make alcoholrelated legislation and control on excise rates, production, distribution and sale of alcohol in their states. Only three states are there which have complete or partial prohibition on alcohol namely Gujarat (complete prohibition), Bihar (complete prohibition) and Manipur (partially prohibited). The Government of Manipur lifted the ban of alcohol in some districts because of some traditions of some scheduled castes and scheduled tribes in these districts. But trade of illicit liquor are flourished along the borders because there is no prohibitionon alcohol in neighboring states. In addition, due to prohibition of alcohol in these states people have begun other substances for addiction like narcotic drugs, as a result illicit trade of narcotic drugs are raising [9, 29, 30].

\subsection{Legal drinking age in various states of India}

Legal drinking age is the minimum age after which a person is allowed to buy alcohol. The legal age in different states in India is given in Table 5 [31].

Table 5 Legal drinking age in various states of India

\begin{tabular}{|l|c|}
\hline Name of state/Union territory & Age in years \\
\hline Goa, Haryana, Himachal Pradesh, Jammu \& Kashmir, Puducherry, Sikkim & 18 \\
\hline $\begin{array}{l}\text { Andaman and Nicobar, Arunachal Pradesh, Andhra Pradesh, Uttar Pradesh, Assam, } \\
\text { Jharkhand, Telangana, Tamilnadu }\end{array}$ & 21 \\
\hline Chandigarh, Daman and Diu, Delhi, Punjab & 25 \\
\hline Gujarat, Bihar, Lakshadeep, Nagaland & Complete ban \\
\hline Manipur & Partial ban \\
\hline
\end{tabular}

\section{Treatment options for Alcohol abuse and alcoholism [33]}

The alcoholism can't be treated only by medicines but it requires strong family and social support too. Treatment for alcohol dependence is achieved usually by stepped therapy, group support, counseling along with medications. Medically, alcohol dependence is treated by three oral medications i.e. Disulfiram, Naltrexone and Acamprosate and a parenteral drug i.e. Naltrexone. These drugs helps in reducing drinking, relapses and leads to full recovery and temperance from alcohol. 


\section{Conclusion}

Alcohol consumption is emerging as a major public health problem in our country. Alcohol consumption not only affects a person's health but his/her mind, body and soul also. Government of India is taking many steps through sensitization programmes and health education campaigns to educate/aware people about the negative impacts of alcohol consumption i.e. social, mental and economic but this much is not enough. Many things or steps are needed to take. Alcohol policy differs from state to state; hence we would like to recommend policymakers to make a rational/uniform alcohol control policy with specific objectives like alcohol taxation, minimum age, production and promotion policy and also the liquor shops must be far from residential, public or market place. There are many Government rules and regulations, they must be strictly followed. It's a strong need because it's a matter of physical, mental and social health and definitely the steps will lower down the illegal trafficking, number of deaths and alcohol use diseases as well.

\section{Compliance with ethical standards}

\section{Acknowledgments}

We would like to deliver our sincere thanks to the authors of the articles mentioned in the reference, due to whom I succeeded in writing this article in a better and beneficial way.

\section{Disclosure of conflict of interest}

The authors declare that they have no competing interests.

\section{References}

[1] World Health Organization (WHO). Global Status Report on Alcohol and Health. 2014. Available from: http://www.who. int/substance_abuse/publications/global_alcohol report/msb_gsr_2014_1.pdf?ua=1.

[2] Eashwar VM, Umadevi R, Gopalakrishnan S. Alcohol consumption in India- An epidemiological review. J family med prim Care. 2020;9(1):49-55.

[3] Nayak MB, Bond JC, Cherpitel C. Detecting alcohol related problems in developing countries: A comparison of screening measures in India. Alcohol Clin Exp Res. 2009;33:2057-66.

[4] www. byjus.com. chemistry of ethyl alcohol

[5] Food Safety and Standards (Alcoholic Beverages) Regulations, 2018, Ministry of Health and Family Welfare (Food Safety and Standards Authority of India), Government of India, Notification, New Delhi, 19th March, 2018

[6] J. Brick, Alcohol Pharmacology. Intoxikon International. Alcohol and Drug Studies.

[7] Naimi TS, Brewer RD, Mokdad A, Denny C, Serdula MK, Marks JS. Binge drinking among US adults.JAMA. 2003; 289:70-75.

[8] National Institute on Alcohol Abuse and Alcoholism. Alcohol Alert. No. 30 PH 359 October 1995, Updated October 2000. Diagnostic Criteria for Alcohol Abuse and Dependence.

[9] World Health Organization. Burden and socio-economic impact of alcohol: The Bangalore study. WHO Regional Office for South-East Asia; 2006. Available from: http://www.searo. who.int/entity/mental_health/documents/9290222727.pdf.

[10] Ambekar A, Agrawal A, Rao R, Mishra AK, Khandelwal SK, Chadda RK. The National Survey on Extent and Pattern of Substance Use in India 2019, Magnitude of Substance Use in India, National Drug Dependence Treatment Centre (NDDTC), All India Institute of Medical Sciences (AIIMS), Ministry of SocialJustice and Empowerment, Government of India, New Delhi, 2019.

[11] Sachdeva S, Nagar M, Tyagi AK, Sachdeva R. Alcohol consumption practices amongst adult males in a rural area of Haryana. Med J DY Patil. 2014; 7:128-32.

[12] World Health Organization. The World Health Report 2002. Reducing Risks, Promoting Health Life. Geneva. Available from: https://www.who.int/whr/2002/en/whr02_en.pdf?ua=1.

[13] World Health Organization. Regional Office for south east Asia. Prevention of harm from alcohol use. Available from: http://apapaonline.org/data/Regional_Data/SEARO/Alcohol_Facts_and_Figures.pdf. 
[14] World Health Organization. Global Health Observatory data repository. Available from: http://apps.who.int/gho/data/ node.main.A1109?lang=en.

[15] Jagadeesan S, Patel P. Epidemiology, pattern and prevalence of alcohol consumption in India: need for public health action. International Journal of Community Medicine and Public Health. 2021; 8(4):2070-76.

[16] Bagnardi V, Blangiardo M, Vecchia CL, Corrao G. Alcohol consumption and the risk of cancer: A meta analysis. Alcohol Res Health. 2001; 25:263-70.

[17] Kasper DL, Fauci AS, Hauser SL, Longo DL, Jameson JL, Loscalzo J. Harrison's principles of internal medicine. 19th ed. New York: McGraw Hill Education; 2012.

[18] Chandra P, Krishna V, Benegal V, Ramakrishna J. High risk sexual behaviour and sensation seeking among heavy alcohol-users. Indian J Med Res. 2003; 117:88-92.

[19] Venkat KK, Arora MM, Singh P, Desai M, Khatkhatay I. Effect of alcohol consumption on bone mineral density and hormonal parameters in physically active male soldiers. Bone. 2009; 45:449-54.

[20] National Institute on Alcohol Abuse and Alcoholism. Alcohol Alert. 2004. Available from: https://pubs.niaaa.nih.gov/publications/aa63/aa63.htm.

[21] Peng MC, Chou WJ, Chen SS. Neurological problems in chronic alcoholics. Gaoxiong Yi XueKeXueZaZhi. 1991; 7:404-12.

[22] Gururaj G, Isaac MK. Psychiatric Epidemiology in India: Moving Beyond Numbers. An Indian Perspective. New Delhi: Elsevier Publications; 1993.

[23] Vijayakumar L, Rajkumar S. Are risk factors for suicides universal? A case- control study in India. ActaPsychiatr Scand. 1999; 99:407-11.

[24] Benegal V, Velayudan A, Jain S. The social costs of alcoholism (Karnataka). NIMHANS J, 2000; 18:67-76.

[25] Gururaj G, Benegal V. Driving under the influence of alcohol and road traffic injuries in Bangalore - Project Report. National Institute of Mental Health and Neurosciences Bangalore, India. 2002. Available from: http://nimhans. ac.in/cam/sites/default/files/Publications/33.pdf.

[26] Adityanjee, Mohan D, Wig NN. Alcohol related problems in the emergency room of an Indian general hospital. Aust N Z J Psychiatry. 1989; 23:274-78.

[27] Drunk driving accidents in states: What numbers say. Available from: http://indianexpress.com/article/explained/drunk driving accidents in states what numbers say 4599876/.

[28] Alcoholics Anonymous. Available from http://www.aa.org

[29] India. Udta Bihar: Huge spike in substance abuse, alcohol bootlegging year after ban. Available from:http://indiatoday.intoday.in/story/india today exclusive investigation udta Bihar black marketing alcohol drugs ban/1/968459.html.

[30] Hooch Tragedy. A hooch tragedy that killed five people rekindles old debate about prohibition in Manipur. Available from: https://scroll.in/article/845997/a hooch tragedy that killed five people rekindles old debate about prohibition in Manipur.

[31] Eattreat.The Legal Drinking Age In Delhi Is The HIGHEST In The Country! But Where Is It the Lowest?. 2019. Available from: https://eattreat.in/india/food and drink/ legal drinking age in india.

[32] Regulationand Legislation. Licensing Laws. Available https://www.alcoholwebindia.in/content/regulation legislation.

[33] Williams SH. Medications for Treating Alcohol Dependence. Am Fam Physician. 2005; 72:1775-80. Available from http://www.aafp.org/afp/2005/1101/p1775.html 


\section{Author's short Biography}

Mr. Tapan Kumar Mahato, presently working as Assistant Professor in Department of
Pharmaceutical Analysis, B. Pharmacy College Rampura (Kakanpur), Godhra, District Panchmahal,
Gujarat, India. His experience is 13 years (10 in teaching and 03 in research) and area of research
is herbal antiulcer drugs. 06 papers and 01 book chapter has been published in his credit till date
in various Journals/Book of national/international repute and presented 08 papers orally/poster
in various seminars/conferences.

